\title{
\begin{tabular}{l|l} 
pcori). & PATIENT-CENTERED OUTCOMES RESEARCH INSTITUTE \\
RESEARCH SUMMARY
\end{tabular}
}

\section{Comparing Ways to Support Shared Decision Making about Birth Control Methods during Healthcare Visits}

Principal investigator

Organization

Rachel Thompson, PhD, BPsychSci(Hons)

Dartmouth College

\section{What was the research about?}

Many kinds of birth control are available. Shared decision making, or SDM, can help patients choose birth control methods that are right for them. In SDM, patients and healthcare providers work together to make healthcare decisions.

In this study, the research team looked at new ways of supporting SDM about birth control methods at clinic visits. These new ways were

- A video that patients watched right before their visit. The video coached patients on asking their provider three questions before any health decision. Patients also received cards to remind them to ask these questions.

- Decision aids about birth control options. Decision aids help people choose between two or more healthcare options based on what's most important to them.

The research team compared these new ways with usual care.

\section{What were the results?}

None of the new ways were better than usual care at supporting SDM about birth control methods.

\section{Who was in the study?}

The study included 5,018 patients. All had a visit at a clinic in the northeast United States. Of patients, 87 percent identified as White, 3 percent as Black or African American, and 3 percent as Asian. Further,
1 percent identified as American Indian or Alaska Native, less than 1 percent as Native Hawaiian or Other Pacific Islander, 2 percent as some other race, and 4 percent as two or more races. Also, 93 percent identified as not being of Hispanic, Latino, or Spanish origin while 7 percent identified as being of Hispanic, Latino, or Spanish origin.

\section{What did the research team do?}

The research team split 16 clinics into four groups according to how often they use SDM. The team assigned the groups by chance to use the video, decision aids, both, or neither. Materials were in English and Spanish. All clinics provided usual care for birth control during the study.

Patients completed surveys after their visit and four weeks and six months later.

The research team included patients, patient advocates, providers, and researchers.

\section{What were the limits of the study?}

Fewer people than expected completed the surveys, which may have affected results.

Future research could continue to look at ways to support SDM about birth control methods.

\section{How can people use the results?}

Clinics can use these results when choosing ways to support SDM about birth control methods.

To learn more about this project, visit www.pcori.org/Thompson348. 